\title{
ORQUIDÁRIO: UMA ABORDAGEM PARA PROMOVER A APRENDIZAGEM SIGNIFICATIVA NO ENSINO DE CIÊNCIAS E SENSIBILIZAR SOBRE A EDUCAÇÃ̃ AMBIENTAL
}

\section{ORCHIDARIUM: AN APPROACH TO PROMOTE MEANINGFUL LEARNING IN SCIENCES TEACHING ABOUT ENVIRONMENTAL EDUCATION}

\author{
Erivaldo Almeida de Souza Filho* \\ ORCID: http://orcid.org/0000-0001-5911-705X \\ Macélia dos Santos Moraes** \\ ORCID: http://orcid.org/0000-0002-3020-8924 \\ Klenicy Kazumy de Lima Yamaguchi ${ }^{* * *}$ \\ ORCID: http://orcid.org/0000-0001-7998-410X
}

RESUMO:

Este trabalho teve como objetivo estimular a aprendizagem no ensino de Ciências mediante a atividade extensionista de aplicação dos conhecimentos botânicos, ecológicos e ambientais na comunidade, abordando sobre o cultivo de orquídeas e estimulando a valorização da flora amazônica e a reflexão sobre conservação ambiental. O projeto foi realizado em uma turma de $7^{\circ}$ ano do Ensino Fundamental, em uma Escola Municipal da rede pública no município de Coari, Amazonas, Brasil. A avaliação do projeto foi realizada por meio da aplicação de questionário inicial e final. A intervenção seguiu as seguintes etapas: 02 (duas) aulas teóricas sobre a temática; palestra sobre preservação ambiental; confecção de um jornal didático; oficina de cultivo e manutenção de orquídeas e exposição de algumas espécies de orquídeas. Os resultados mostraram que antes da realização das atividades os próprios alunos reconheceram o pouco entendimento sobre preservação ambiental. As atividades realizadas abordando os conhecimentos botânicos, ecológicos, preservação e valorização da flora regional proporcionaram um contato direto com a vivência prática dos assuntos que foram estudados na sala de aula.

Palavras chave: Preservação ambiental; Orquídeas; Ensino fundamental.

\begin{abstract}
:
This work aimed to stimulate learning in science teaching through a university outreach project with botanical, ecological and environmental knowledge about orchid cultivation, stimulating the appreciation of the Amazonian flora and reflection on environmental conservation. The project was carried out in a 7th grade elementary school class at a public school in Coari, Amazonas, Brazil. The project evaluation was carried out through the application of initial and final questionnaires. The intervention followed the following steps: 02 (two) theoretical classes on the theme; a lecture on environmental preservation; creation of an educational journal; orchid cultivation and maintenance workshop and exhibition of some orchid species. The results showed that prior to the activities the students themselves recognized their little understanding of environmental preservation. The activities carried out addressing the botanical, ecological knowledge, preservation and enhancement of the regional flora, provided a direct contact with the practical experience of the subjects that were studied in the classroom.
\end{abstract}

Keywords: Environmental preservation; Orchids; Elementary school.

\footnotetext{
* Aluno de Graduação da Universidade Federal do Amazonas (UFAM), Coari - AM, Brasil. E-mail: erivaldo97souza@gmail.com

${ }^{* *}$ Professora da Universidade Federal do Amazonas (UFAM), Coari - AM, Brasil. E-mail: macelia_araujo@hotmail.com

${ }^{* * *}$ Professora da Universidade Federal do Amazonas (UFAM), Coari - AM, Brasil. E-mail: klenicy@gmail.com
} 


\section{Introdução}

Os Parâmetros Curriculares Nacionais versam que o ensino de Ciências Naturais deve ser organizado de forma que ao final do Ensino Fundamental os alunos tenham a capacidade de compreender a natureza como um todo dinâmico, sendo o ser humano parte integrante e agente de transformações do mundo em que vive (BRASIL, 1997).

A Amazônia apresenta uma grande variedade de espécies vegetais, biodiversidade que muitas vezes passa despercebida nas aulas de Ciências, delineando, em muitos casos, em conhecimentos botânicos e ecológicos desvinculados do cotidiano e regionalidade dos educandos. Barbosa et al. (2016) salienta que apesar da existência de uma grande diversidade nos diferentes ecossistemas, a realidade do ensino de botânica nas escolas é marcada pelo desinteresse e desmotivação.

Uma das espécies da flora amazônica que pode ser utilizada como ferramenta didática são as orquídeas. Nonciboni e Royer (2010) citam que a família Orchidaceae é a mais numerosa do reino vegetal, presente em todas as partes do globo, exceto no polo sul. Os autores salientam ainda que o Brasil é um dos países mais ricos em orquídeas, comparável somente à Colômbia e ao Equador. Estudos recentes registram cerca de duas mil e trezentas espécies para o território brasileiro. Existem em maior número de espécies nas regiões tropicais e subtropicais, em altitudes não superiores a dois mil metros. Complementando, Raposo (1992) afirma que muitas orquídeas, principalmente as que vivem nas regiões frias ou temperadas, crescem no solo, sendo chamadas de terrestres. Já nas zonas tropicais e subtropicais, a predominância das espécies ocorre nas florestas onde a umidade atmosférica é muito alta, com dias relativamente quentes e noites mais frescas. Na sua maioria, vivem sobre as árvores e são denominadas de epífitas.

As orquídeas apresentam elementos que propiciam ao professor uma abordagem e mediação dos conhecimentos botânicos, ecológicos e ambientais, tendo em vista que estas encantam por sua beleza natural e exibem peculiaridades ecológicas. Infelizmente, muitas de suas espécies estão ameaçadas de extinção, seja por retiradas indevidas ou pela devastação crescente da floresta.

Diante da ameaça que muitas espécies de orquídeas sofrem, torna-se fundamental levantar em sala de aula esta problemática. Filho et al. (2015) reitera que a ornamentação do orquidário, aliada às discussões realizadas em sala de aula, é eficaz para a sensibilização dos educandos quanto à Educação Ambiental, gerando nestes a consciência que não podem extrair nenhum espécime vegetal da natureza.

De acordo com a Lei 9.795/99, o Artigo 1o destaca a Educação Ambiental como processos por meio dos quais o indivíduo e a coletividade constroem valores sociais, conhecimentos, habilidades, atitudes e competências voltadas para a conservação do meio ambiente (BRASIL, 1999). A referida Lei ratifica ainda no Artigo $2^{\circ}$ que a Educação Ambiental é um componente essencial e permanente da educação nacional que visa propiciar o aumento do conhecimento, mudança de paradigmas e aperfeiçoamento de habilidades em prol do meio ambiente. Dessa forma, precisa estar presente, em todos os níveis e modalidades do processo educativo, seja ele em caráter formal ou informal, buscando estimular a compreensão e a reflexão dos indivíduos participantes sobre sua própria realidade histórica, construída pelas relações sociais (CAVALCANTI, 2010).

Ao enfatizar a eficácia do uso de uma família botânica, mais especificamente as Orchidaceae, como tema gerador de um debate, Peluzio e Soares (2008) dizem que estas constituem ferramentas eficazes para ser uma "porta que leva à Educação Ambiental", que sensibilizam suficientemente os alunos para trilharem no caminho que cumpre todas ou parte das finalidades e objetivos da Educação Ambiental. Contudo, a Educação Ambiental não é um instrumento que soluciona os problemas ambientais, mas que participa do desenvolvimento pessoal socioeducativo, contribuindo para a formação de cidadãos mais conscientes em relação a atitudes que podem causar danos ao meio ambiente. Ela é capaz de formar pessoas propagadoras de ideias ecologicamente corretas, amenizando impactos e tornando possível a construção de um ambiente com um cenário mais agradável e preservado (SAUVÉ, 2005). 
Embora a floresta amazônica faça parte do contexto onde as escolas estão inseridas, notou-se durante o período de Estágio Supervisionado de Ensino que a importância dada à utilização da flora como recurso didático para ensinar e aprender no Ensino Fundamental, nem sempre gera um impacto significativo na aprendizagem dos alunos. Dessa forma, observou-se a necessidade de desenvolver um projeto intervencionista que oportunizasse aos alunos o contato com espécies de uma família Orchidaceae, por toda sua peculiaridade.

Nesse contexto, ações extensionistas são de suma importância para aproximar os saberes da comunidade e os científicos, integrando as dimensões ecológicas, social e econômica em prol de uma maior conscientização sobre o valor que os recursos naturais apresentam. Segundo Carvalho et al. (2020), a interação entre a Universidade e as comunidades, nos projetos de extensão, geram benefícios a todos os envolvidos, pois conciliam a conservação ambiental com o desenvolvimento socioeconômico.

Nessa perspectiva, este trabalho objetivou estimular a aproximação dos conhecimentos botânicos, ecológicos e ambiental com abordagens teórico-práticas, estimulando a valorização da flora amazônica por meio da reflexão sobre conservação ambiental. Para isso, buscou-se sensibilizar a comunidade, levando-a a reconhecer a importância das orquídeas para o meio ambiente, oportunizando a aquisição de conhecimentos e habilidades necessárias para torná-la agente de sua própria aprendizagem. Assim sendo, formam-se cidadãos conscientes nas tomadas de decisões que priorizem a sustentabilidade.

\section{Material e método}

A atividade extensionista foi realizada em uma escola municipal no município de Coari, Amazonas, Brasil, como atividade de um projeto do curso de Ciências: Biologia e Química, da Universidade Federal do Amazonas. Participaram das atividades 37 alunos de uma turma de $7^{\circ}$ ano do Ensino Fundamental.

O projeto caracterizou-se como uma pesquisa em interface com extensão, de caráter qualitativo e quantitativo, tendo o enfoque a valorização da biota Amazônica por meio do uso de algumas espécies da família Orchidaceae como intermediadoras da aprendizagem.

Primeiramente, foi apresentada a proposta metodológica à direção da escola, à professora que ministra a disciplina de Ciências Naturais na turma do $7^{\circ}$ ano, bem como aos alunos da referida turma, com a finalidade de formação de parceria para a execução do projeto. A atividade apresenta CAAE: 20067619.4.0000.5020.

Para a execução da ação extensionista foram feitos levantamentos bibliográficos objetivando o embasamento acerca da temática trabalhada. A aplicação da intervenção na escola ocorreu no período de 01/04/2019 a 24/04/2019 e seguiu as seguintes etapas:

$1^{\text {a }}$ Etapa - Os alunos responderam voluntariamente a um questionário inicial constituído de 12 (doze) questões fechadas, que teve o objetivo de levantar dados sobre os conhecimentos prévios dos educandos quanto à temática que posteriormente foi trabalhada.

$2^{\text {a }}$ Etapa - Foram ministradas 02 (duas) aulas teóricas contextuais de 45 minutos cada, abordando os seguintes tópicos: principais características morfológicas e importância ecológica das orquídeas. Foi levantada a problematização referentes a questões sobre espécies de orquídeas ameaçadas de extinção, desequilíbrios ambientais e conservação da flora amazônica. Para a realização dessa etapa, foram utilizados recursos como: quadro branco, pincel, livro didático e data show.

$3^{\mathrm{a}}$ Etapa - Foi realizada uma palestra sobre preservação do Meio Ambiente realizada em parceria com a Secretaria Municipal do Meio Ambiente que disponibilizou uma Engenheira ambiental como palestrante. A palestra foi realizada com a projeção de slides sobre o tema e exibição do vídeo sobre a carta escrita no ano 2070. 
$4^{\mathrm{a}}$ Etapa - Ocorreu a elaboração e confecção de um jornal didático. A turma foi dividida em grupos com cinco alunos. Cada grupo ficou responsável pela pesquisa dos conhecimentos que foram expostos no jornal, assim como pela a elaboração do mesmo. Os alunos colaram em papeis A4 recortes de imagens de algumas espécies de orquídeas e escreveram manualmente todos os conhecimentos e informações pertinentes ao tema, como segue: conceito de orquídeas; sua morfologia; importância ecológica; algumas espécies ameaçadas de extinção e conservação ambiental. A confecção do jornal ocorreu durante a aula de ciências, mais especificamente em uma aula de 45 minutos. Este teve suas páginas fixadas em um mural durante a realização de uma exposição de orquídeas.

$5^{\text {a }}$ Etapa - Oficina sobre cultivo e conservação de orquídeas - realizada com a participação de um cultivador (orquidiocultor ou orquidófilo) de orquídeas que explicou como cultivar e toda a manutenção necessária para o desenvolvimento e conservação das mudas. O mesmo fez uma demonstração dos procedimentos para o plantio, em seguida os alunos formaram cinco grupos e cada grupo fez o plantio de uma muda de orquídeas que eram de um orquidário particular. Foram utilizados alguns recursos alternativos como: ouriço de castanha do pará (para os jarros), palito de madeira (para o suporte), fita metálica, seixo.

$\mathrm{Na}$ oportunidade, foi enfatizado aos alunos que a extração de qualquer espécime vegetal da natureza pode gerar impacto negativo na harmonia ecológica, além de ser crime ambiental. Dessa forma, as mudas para a ornamentação não podem ser extraídas da natureza, carecendo ser provenientes de doações dos orquidários (particulares ou públicos) ou compradas em floricultura.

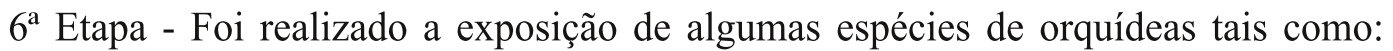
Catasetum macrocarpum, Cattleya luteola, Epidendrum noturnum, Epidendrum coronatum, Galeandra stangeana, Maxillaria diforme, Catasetum gnomus, Catasetuam barbatum, todas disponibilizadas por um orquidário particular apenas para a exposição, que teve como título "O fantástico mundo das orquídeas: aprender para preservar", com a finalidade de mostrar a diversidade e beleza das orquídeas e principalmente a importância de sua preservação. $\mathrm{Na}$ oportunidade, os alunos apresentaram todos os materiais confeccionados durante o projeto (jornal didático e as mudas cultivadas pelos mesmos). A referida exposição foi aberta a toda a comunidade escolar, tendo sua realização na própria escola parceira, em área apropriada para as orquídeas.

$7^{\mathrm{a}}$ Etapa - Aplicação do questionário final - os alunos foram novamente convidados a responder um questionário final, que constava de 10 (dez) questões fechadas, com o objetivo de avaliar a eficácia do projeto.

Ao final do desenvolvimento do projeto, todo material didático confeccionado pelos alunos foi doado para escola, ficando disponível para os demais alunos.

\section{Resultados e discussão}

O ensino de Ciências Naturais vem sendo, muitas vezes, trabalhado desvinculado do contexto regional ao qual os alunos estão inseridos. No interior do estado do Amazonas, os professores têm a sua disposição uma vasta diversidade vegetal que pode ser utilizada como recurso didático que motiva e facilita a aprendizagem na disciplina de Ciências.

Nesse contexto, o projeto propôs atividade extensionista que contextualizasse os conhecimentos botânicos, ecológicos e ambientais, utilizando as orquídeas como ferramenta/símbolo para alertar os alunos quanto a problemas ambientais ocasionados pela devastação de espécies vegetais. 
No quadro e figura 1 , podem ser verificados os resultados obtidos mediante a aplicação do questionário inicial.

Quadro 1 - Resultados obtidos mediante a aplicação do questionário inicial.

\begin{tabular}{|l|c|c|c|}
\hline \multicolumn{1}{|c|}{ Descrição da pergunta } & \multicolumn{2}{c|}{ Resultado em (\%) } \\
\cline { 2 - 4 } & Sim & Não & Parcial \\
\hline Você gosta da disciplina de ciências? & 94,3 & 5,7 & - \\
\hline Você já participou de aulas práticas na disciplina de ciências? & 62,9 & 37,1 & - \\
\hline Você sabe o que é meio ambiente? & 97,1 & 2,9 & - \\
\hline $\begin{array}{l}\text { Em sua opinião, as espécies vegetais são importantes para o meio } \\
\text { ambiente? }\end{array}$ & 97,1 & 2,9 & - \\
\hline Nas aulas de ciências, você já ouviu falar a respeito das orquídeas? & 37,1 & 62,9 & - \\
\hline Você acredita que na região amazônica existem espécies de orquídeas? & 71,5 & 17,1 & 11,4 \\
\hline Você sabe o que é preservação ambiental? & 82,9 & 17,1 & - \\
\hline $\begin{array}{l}\text { Você já ouviu falar a respeito de alguma espécie de planta ameaçada de } \\
\text { extinção? }\end{array}$ & 82,9 & 17,1 & - \\
\hline Você já cultivou (plantou) alguma espécie de planta? & 77,1 & 22,9 & - \\
\hline $\begin{array}{l}\text { Você teria interesse em participar de um projeto que lhe proporcionasse } \\
\text { um contato direto com uma espécie vegetal? }\end{array}$ & 91,4 & 8,6 & - \\
\hline $\begin{array}{l}\text { Você teria interesse em que fosse realizada uma exposição de orquídeas na } \\
\text { sua escola? }\end{array}$ & 77,1 & 22,9 & - \\
\hline
\end{tabular}

Fonte: Autores.

Observou-se que a disciplina de Ciências naturais era uma das matérias do Ensino Fundamental bastante apreciada pelos discentes (94,3\%), representando ponto positivo, pois gostando da disciplina, os mesmos encontravam-se acessíveis para a aquisição de novos conhecimentos. Observou-se ainda que aulas práticas estavam tornando-se cada vez mais presentes nas metodologias dos docentes dessa disciplina.

Constatou-se também que $77,1 \%$ dos educandos afirmaram ter cultivado algum espécime vegetal, o que demonstra que a flora é elemento presente no ambiente dos alunos. Já em relação às orquídeas, embora a maioria dos estudantes $(71,5 \%)$ afirmarem acreditar que na região Amazônica existem espécies de orquídeas, 62,9\% garantiram que nas aulas de Ciências nunca ouviram falar sobre essas espécies especificamente, revelando que os conhecimentos botânicos, ecológicos e ambientais da família Orchidaceae eram pouco abordados nas aulas, carecendo de maiores abordagens. As orquídeas fazem parte do bioma amazônico, uma vez que, segundo Stortia et al. (2011), a floresta amazônica constitui-se de um complexo vegetacional e as orquídeas ocorrem nas diversas tipologias florestais presentes.

No que se refere a conceitos referentes a questões ambientais, nota-se nos resultados iniciais (quadro 1), que a Educação Ambiental vem sendo trabalhada de forma ineficiente e descontextualiza, acarretando, em muitos alunos, a percepção que essa temática não está presente no seu cotidiano. Apesar de parte dos alunos alegarem saber o conceito de meio ambiente $(97,1 \%)$ e preservação ambiental $(82,9 \%)$, de considerarem as espécies vegetais importantes para o meio ambiente $(97,1 \%)$ e afirmarem já terem ouvido falar a respeito de alguma espécie de planta ameaçada de extinção $(82,9 \%)$, informações aparentemente animadoras, os dados expostos na figura abaixo evidenciam uma preocupante incoerência. Esse fato que, segundo Oliveira et al. (2007), justifica-se, muitas vezes, por não haver uma clareza do que seja meio ambiente e Educação Ambiental, refletindo, segundo os autores, em certa deficiência no contexto educacional e, particularmente, no ensino de Ciências quando se trabalha Educação Ambiental. 
Figura 1 - Grau de conhecimento sobre preservação ambiental na perspectiva dos discentes.

\section{Grau de conhecimento dos discentes sobre preservação ambiental}

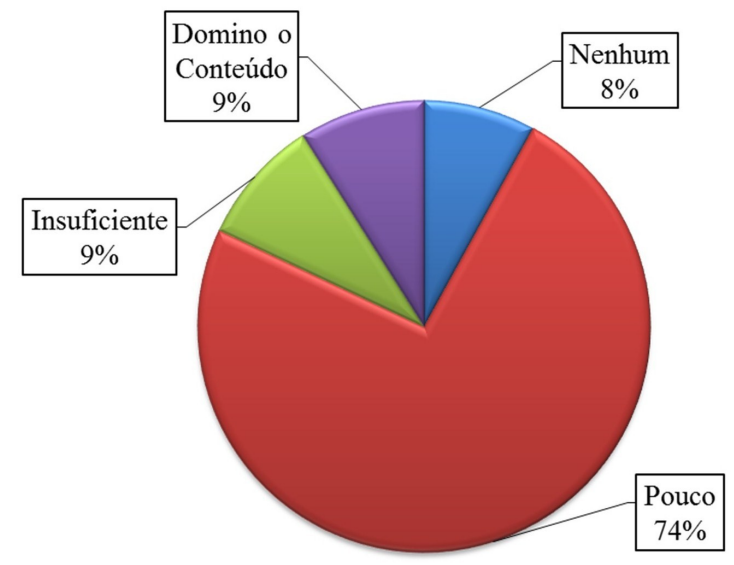

Fonte: Autores.

Verifica-se que, na figura 1, inicialmente, os próprios estudantes, em sua maioria $(74,0 \%)$, consideravam possuir pouco conhecimento sobre preservação do meio ambiente e Educação Ambiental, dado que evidencia a necessidade de um trabalho mais efetivo na abordagem dessa temática no Ensino Fundamental, a fim de provocar nos educandos um senso crítico sobre a relação do ser humano com o meio ambiente. Silva e Leite (2008) citam que para a realização da Educação Ambiental, são imprescindíveis identificar a percepção ambiental dos atores que estão envolvidos no processo e utilizar estratégias metodológicas que permitam a construção e reconstrução do conhecimento de forma dinâmica e criativa. Visão que corrobora com os resultados acurados neste trabalho.

$\mathrm{Na}$ atividade teórica, percebeu-se o interesse dos educandos referente à temática. Nessa etapa, tiveram a oportunidade de expor suas opiniões, fizeram questionamentos e alguns compartilharam suas experiências, fatores que tornaram as aulas mais proveitosas. Notou-se também que referente aos conhecimentos botânicos sobre a morfologia das orquídeas, os mesmos apresentavam até então certa carência que foi sanada durante as aulas. $\mathrm{O}$ ensino de Ciências Naturais também é espaço privilegiado em que as diferentes explicações sobre o mundo, os fenômenos da natureza e as transformações produzidas pelo homem podem ser expostas e comparadas. É espaço de expressão das explicações espontâneas dos alunos e daquelas oriundas de vários sistemas explicativos (BRASIL, 1997).

Salienta-se ainda que contrapor e avaliar diferentes explicações favorece o desenvolvimento de postura reflexiva, crítica, questionadora e investigativa, de não aceitação de ideias e informações sem a devida análise crítica construtiva, colaborando para a construção da autonomia de pensamento e ação.

A apresentação teórica foi uma oportunidade para que o licenciando extensionista pudesse praticar a sua futura profissão docente e os agentes comunitários encontrassem apoio especializado para solucionar as dúvidas e questionamentos sobre o tema.

$\mathrm{Na}$ elaboração e confecção do jornal didático, observou-se a efetiva participação dos alunos que demonstraram dedicação e empenho. Durante a exposição das orquídeas, os discentes ficaram bem descontraídos e maravilhados mediante a observação e contado direto (muitos aproveitaram para tocar nas orquídeas) com os espécimes expostos. $\mathrm{Na}$ ocasião, foi reforçada a importância da preservação de todas as espécies vegetais, classificando a retirada destas de seus habitats naturais como um crime ambiental.

No quadro 2 e figuras 2 e 3 , podem ser verificados os resultados obtidos mediante a aplicação do questionário final. 
ORQUIDÁRIO: UMA ABORDAGEM PARA PROMOVER A APRENDIZAGEM SIGNIFICATIVA NO ENSINO DE CIÊNCIAS E SENSIBILIZAR SOBRE A EDUCAÇÃO AMBIENTAL

Erivaldo Almeida De Souza Filho, Macélia dos Santos Moraes e Klenicy Kazumy de Lima Yamaguchi

Quadro 2 - Resultados obtidos mediante a aplicação do questionário final.

\begin{tabular}{|c|c|c|c|}
\hline \multirow{2}{*}{ Descrição da pergunta } & \multicolumn{3}{|c|}{ Resultado em (\%) } \\
\hline & Sim & Não & Parcial \\
\hline Em sua opinião, as orquídeas são importantes para o meio ambiente? & 100 & - & - \\
\hline Você saberia identificar algum espécime de orquídea? & 75,7 & 13,5 & 10,8 \\
\hline $\begin{array}{l}\text { Você saberia identificar algum beneficio ambiental ou ecológico } \\
\text { proporcionado pela presença das espécies vegetais? }\end{array}$ & 46,0 & 21,6 & 32,4 \\
\hline Você considera importante preservar as espécies vegetais? & 94,6 & 05,4 & - \\
\hline $\begin{array}{l}\text { As atividades realizadas facilitaram a compreensão dos conteúdos de } \\
\text { Ciências? }\end{array}$ & 91,9 & 2,7 & 5,4 \\
\hline $\begin{array}{l}\text { Você gostaria que essa metodologia de ensino fosse aplicada mais vezes } \\
\text { para abordar os conteúdos de Ciências? }\end{array}$ & 83,8 & 08,1 & 08,1 \\
\hline $\begin{array}{l}\text { Em sua opinião, a realização do projeto despertou em você o interesse em } \\
\text { aprender os conteúdos de Ciências? }\end{array}$ & 91,9 & 02,7 & 05,4 \\
\hline
\end{tabular}

Fonte: Autores.

Analisando os dados do quadro 2, verifica-se que trabalhar em sala de aula a Educação Ambiental com dinamismo, tornando os alunos sujeitos ativos na construção de sua aprendizagem, é uma estratégia eficaz de ensino. Corroborando, 94,6\% dos discentes avaliaram ser importante preservar as espécies vegetais. A turma foi unânime na compreensão da importân-cia das orquidáceas para o meio ambiente $(100 \%)$, afirmando que saberiam identificar algum espécime de orquídeas (75,7\%), sendo as mais citadas a Cattleia luteola e Epiderchum fragras.

Fernandes e Lima (2018) ressaltam que a educação não deve se estruturar apenas no ambiente escolar, mas deve expandir-se em diferentes meios de propagação, principalmente na extensão universitária, contribuindo, assim, como mecanismo de conscientização para o equilíbrio do meio ambiente.

As informações obtidas constataram que a maioria dos discentes $(83,8 \%)$ gostariam que esse tipo de metodologia fosse aplicado mais vezes nas abordagens, pois segundo os mesmos, atividades como as que foram realizadas facilitam a compreensão $(91,9 \%)$ e despertam o interesse em aprender os conteúdos de Ciências Naturais (91,9\%), demonstrando a importância da realização de projetos intervencionistas como este.

Figura 2 - Perspectiva dos discentes para cada atividade realizada durante o projeto.

\section{Motivação dos discentes quanto as atividades} realizadas

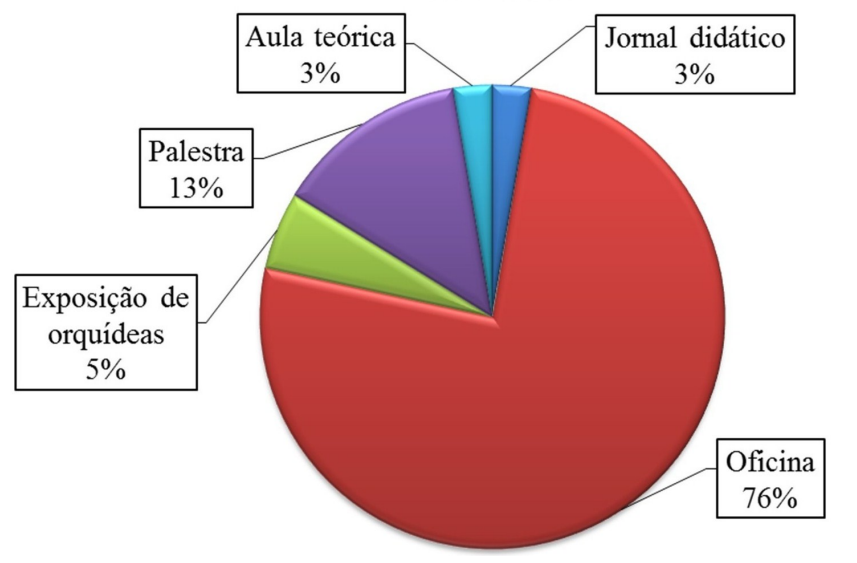

Fonte: Autores.

Em se tratando das atividades que os educandos mais gostaram de participar, observa-se que proporcionar aos alunos o contato direto com uma espécie vegetal tornase uma excelente alternativa de ensino, despertando a motivação para a aprendizagem significativa. Essa observação é corroborada por outros autores (SILVA; LOPES, 2007) ao trabalharem com atividades relacionadas aos conceitos botânicos. 
Verificou-se a efetiva participação dos discentes na oficina sobre cultivo e conservação de orquídeas, em que os mesmos tiveram a oportunidade de verificar de perto a morfologia de alguns exemplares de orquídeas, aprenderam a cultivar e todos os cuidados que elas necessitam para sua manutenção. Durante a oficina, os alunos demostraram muita curiosidade e admiração quanto às orquídeas, querendo participar de todas as etapas do plantio das mesmas, pois segundo alguns alunos, eles já haviam feito o plantio de espécies vegetais em suas residências, contudo não de orquídeas. No final, as cinco mudas de orquídeas foram doadas para a escola, caracterizando o início de criação de um orquidário.

O plantio de espécies vegetais são temas geradores importantes nesse processo de conscientização, pois por meio dele é possível estimular o alcance da compreensão sistêmica que a questão socioambiental exige (LEMOS; MARANHÃO, 2008).

Os autores reiteram ainda o papel social que as universidades exercem em ações extensionistas, estimulando os participantes a terem uma consciência crítica social, contribuindo para a busca de soluções de problemas nos locais em que essas instituições estão inseridas, sendo uma missão social e um exercício da cidadania para a construção de uma sociedade mais desenvolvida.

Os processos educadores coletivos que foram realizados, mediante o esclarecimento sobre a importância da preservação do meio ambiente, a biota Amazônica e a oficina de cultivo de espécies, no caso deste trabalho, as orquídeas, trouxe aos participantes o sentimento de pertencimento, repercutindo positivamente em ações proativas e transformadoras da extensão ao aproximar a relação entre universidade e sociedade.

Outra atividade de relevância que chamou a atenção dos alunos foi a palestra sobre meio ambiente realizada por uma engenheira ambiental vinculada à Secretaria Municipal do Meio Ambiente, ocasião em que os alunos aprenderam e discutiram a importância do meio ambiente para os seres vivos, bem como sobre a preservação das orquídeas e seu valor ecológico. Os participantes interagiram durante a palestra, principalmente quando foi salientada a importância da manutenção de algumas espécies vegetais no seu habitat natural. Aprenderam também que para a retirada de espécies, sejam elas vegetais ou animais, da natureza, é necessário a autorização dos órgãos competentes (IBAMA - Instituto Brasileiro do Meio Ambiente e dos Recursos Naturais Renováveis e Secretaria do Meio Ambiente).

Segundo Silva (2006), as atividades extensionistas são enriquecidas com a articulação das administrações públicas (municipal, estadual e federal) com a universidade, ratificando-se, no entanto, que a universidade não substitui o poder público em suas funções constitucionais, mas soma conhecimento e participação em prol de um objetivo comum.

Os educandos ficaram sensibilizados em relação ao que foi abordado, resultado também alcançado por Filho et al. (2015) ao evidenciarem que todos os educandos foram sensibilizados em relação à extração de espécies vegetais para ornamentação no trabalho sobre a importância de orquídeas para o meio ambiente.

Um dos momentos de inteira atenção ocorreu quando a palestrante exibiu um vídeo sobre a carta escrita no ano 2070, que retrata os problemas que a humanidade terá se continuar com descaso para com o meio ambiente, dando ênfase à poluição dos recursos hídricos. Ao final da palestra, alguns alunos fizeram perguntas tais como: As espécies vegetais são importantes para a natureza? Outros participaram expondo suas opiniões. 
Figura 3 - Classificação de satisfação para o projeto de intervenção na perspectiva dos alunos.

\section{Satisfação dos discente sobre o projeto}

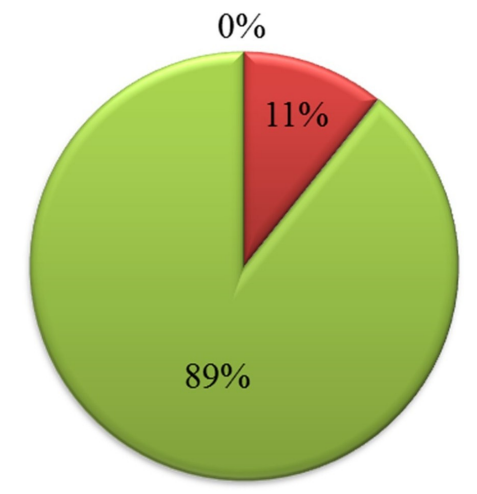

$\square$ Regular

Bom

$\square$ Ótima

Fonte: Autores.

A atividade extensionista realizada foi de suma importância para a sensibilização dos discentes, obtendo ótima participação e avaliação dos alunos, mostrando que a extensão universitária possibilitou a articulação entre o conhecimento científico abordado em sala de aula e as problemáticas que se fazem presentes no cotidiano dos discentes, despertando o senso crítico e oportunizando uma formação social. Colaborando com este entendimento, Neumann et al. (2018) acreditam que os debates críticos para compreensão do contexto social em que vivem, além de contribuir para que os alunos usufruam dos bens e recursos necessários à sobrevivência, apresentam uma relação harmônica com o meio natural e social.

Tal qual a premissa que versa sobre as atividades extensionistas (SILVA, 2006), verificou-se, por meio dos resultados, que houve a democratização do saber acadêmico, propiciando à comunidade a ressignificação do conhecimento relacionado ao meio ambiente. Verificou-se, além disso, que as atividades realizadas contribuíram para fortalecer a relação social entre os discentes participantes e o acadêmico universitário sendo um momento de interação interdisciplinar.

Espera-se que ações extensionista como essa possam ocorrer, aproximando a participação de diferentes profissionais e instituições em prol da popularização do conhecimento e do desenvolvimento da região.

\section{Conclusão}

Ensinar e aprender sobre a importância dos recursos naturais exige, sobretudo, motivação. O desenvolvimento do projeto evidenciou que a Educação Ambiental quando trabalhada de maneira integrante, fornece instrumentos necessários aos alunos para tornarem-se sujeitos ativos, reflexivos e capazes de construir valores socioambientais que contribuem para a formação de cidadãos conscientes. A atividade de extensão pôde proporcionar uma aproximação dos acadêmicos participantes com a comunidade, interagindo e relacionando os conteúdos teóricos com a prática dos futuros docentes. Além disso, conseguiu integrar os saberes prévios dos alunos com a aplicação social da importância da preservação do meio ambiente.

Os resultados revelaram também que proporcionar o contato direto com uma espécie vegetal específica é uma excelente estratégia de sensibilização que conduz e produz uma aprendizagem significativa, demonstrando assim que o objetivo deste trabalho de sensibilizar sobre a importância da preservação ambiental mediante a contextualização dos conhecimentos botânicos e ecológicos com orquídeas, foi alcançado com sucesso. 


\section{Referências}

BARBOSA, T. J. V. et al. Atividades de ensino em espaços não formais amazônicos: um relato de experiência integrando conhecimentos botânicos e ambientais. Revista brasileira de Educação Ambiental. São Paulo, v. 11, n 4, p.174-183, 2016. Disponível em: https://pdfs.semanticscholar.org/ede5/f5d3bbcf01c3cca8f16c789f5abdc4bbb4df.pdf

BRASIL. Lei Federal n 9.795, de 27 de abril de 1999. Dispõe sobre a Educação Ambiental, institui a Política Nacional de Educação Ambiental e dá outras providências. Brasília, DF. Ministério do Meio Ambiente/MEC, 1999. Disponível em: http://www.planalto.gov.br/ccivil_03/leis/19795.htm

BRASIL. Secretaria de Educação Fundamental. Parâmetros curriculares nacionais: ciências naturais/Secretaria de Educação Fundamental - Brasília: MEC/SEF, 1997. Disponível em: http://portal.mec.gov.br/seb/arquivos/pdf/livro04.pdf

CARVALHO, N. R.; BARATA-SILVA, A. W.; PEREIRA, V. S.; GOMES, L. A. Entensão universitária em comunidade rural: diálogos para conservação da Araucaria angustifolia. Revista Conexão UEPG, v.16, e2013566, p.1-12, 2020.

CAVAlCANTI, J. A.; FREITAS, J. C. R de.; MELO, A. C. N de.; FREITAS FILHO. J. R. Agrotóxicos: uma temática para o ensino de química. Química Nova Escola, v. 32, n.1, p. 31-36, 2010.

FERNANDES, P.H. C.; LIMA, L. V. A. Meio ambiente: a extensão na Operação Forte dos Reis Magos do Projeto Rondon em Acari, Rio Grande do Norte. Em Extensão, v. 17, n. 2, p. 235-253, 2018.

FILHO, M. V. C. et al. Repensando o extrativismo vegetal a partir de uma prática educativa com orquídeas. Enciclopédia Biosfera, Centro Científico Conhecer - Goiânia, v.11, n.2, p. 2754, 2015. Disponível em: http://docplayer.com.br/59482483-Repensandoo-extrativismo-vegetal-a-partir-de-uma-pratica-educativa-com-orquideas.html

LEMOS, G. N.; MARANHÃO, R. R. O Viveiro Educador como espaço para a Educação Ambiental. Revista Ambientalmente Sustentable, v. 2, n. 6, p. 173-190, 2008.

NEUMANN, S. et al. Educação Ambiental no Ensino Fundamental: plantando sementes, colhendo consciência. Poíesis Pedagógica, Catalão-GO, v. 16, n.1, p. 26-43, jan./jun. 2018. Disponível em: https://www.revistas. ufg.br/poiesis/article/download/37350/26741

NONCIBONI, M. L. P.; ROYER, M. R. Orquidário Natural: uma ferramenta para Educação Ambiental. In: O Professor PDE e os Desafios da Escola Pública Paraense. Vol. I, 2010. Disponível em: http://www.diaadia educacao.pr.gov/portals/caderno/pdebusca/producoes_pde/2010/2010

OLIVEIRA, A. L. et al. Educação Ambiental: concepções e práticas de professores de ciências do ensino fundamental. Revista Electrónica de Enseñanza de las Ciencias, v. 6, n.3, p.471495, 2007. Disponível em: http://reec.uvigo.es/volumenes/volumen6/ART1_Vol6_N3.pdf

PELUZIO, L. E.; SOARES, M. N. Orquídeas: porta aberta para a Educação Ambiental. 2008. Disponível em: http://www.coluni.ufv.br/ revista-antiga/docs/volume01/orquideas.pdf

RAPOSO, J. G. A etimologia a serviço dos orquidófilos. São Paulo, v.1, ed. Ave-Maria, 1992.

SAUVÉ, L. Educação Ambiental: possibilidades e limitações. Educação e Pesquisa.

Revista da Faculdade de Educação da USP, v. 31, n. 2, p. 317 - 322, 2005. Disponível em: http://www.scielo.br/pdf/ep/v31n2/a07v31n2.pdf 
SILVA, M. M. P.; LEITE, V. D. Estratégias para realização de Educação Ambiental em Escolas do ensino fundamental. Revista eletrônica do Mestrado em Educação Ambiental, v. 20, 2008. Disponível em:

https://periodicos.furg.br/remea/article/view/3855/2299

SILVA, J. N.; LOPES, N. P. G. Botânica no Ensino Fundamental: diagnóstico de dificuldades no ensino e da percepção e representação da biodiversidade vegetal por estudantes. Revista Eletrônica de Ensenanza de lãs Ciências, v. 13, n. 12, p. 115-136, 2014.

SILVA, M. P. M. A arquitetura da extensão na Universidade Federal do Amazonas. Pró-reitoria de Extensão e Interiorização (PROEXTI) - Universidade Federal do Amazonas - UFAM, 2006.

STORTI, E. F. et al. Biologia reprodutiva de Cattleya eldorado, uma espécie de Orchidaceae das campinas amazônicas. Acta Amazonica, vol. 41, n.3, p. 361 - 368, 2011. Disponível em: http://www.scielo.br/scielo.php?script=sci_arttext\&pid=S004459672011000300005 